\title{
The clinical significance of biochemical failure in the first 2 years in patients treated with neo-adjuvant androgen deprivation and radiotherapy for prostate cancer
}

\author{
Fergal C. Kelleher ${ }^{1,2^{*}}$, Dunne $\mathrm{MT}^{1}$, Collins IM ${ }^{1}$, Finn $\mathrm{MA}^{1}$, $\mathrm{O}^{\prime}$ Shea $\mathrm{CM}^{1}$ and Armstrong JG ${ }^{1,2}$ \\ *Correspondence: fergalkelleher@hotmail.com \\ 'St. Luke's Cancer Institute, Highfield Rd, Rathgar, Dublin 6, Ireland. \\ ${ }^{2}$ St. Vincent's University Hospital, Elm Park, Dublin 4, Ireland.
}

\begin{abstract}
Introduction: Biochemical failure in the first 2 years after radical prostatectomy confers an adverse prognosis compared to later biochemical relapse. This supplementary analysis of the Irish Clinical Oncology Research Group Trial 97-01 assess if this is also the case for patients managed with neo-adjuvant hormonal treatment and radiotherapy.

Methods: The Irish Clinical Oncology Group initiated a prospective randomised trial (ICORG 97-01) that compared 4 versus 8 months of neo-adjuvant androgen deprivation therapy (NADT) for patients treated with 3D conformal radiotherapy (RT) for prostate cancer. This supplementary study describes a Cox regression analysis of data from 253 participants in that trial.

Results: In patients with EBF (early biochemical failure) i.e., within 2 years, median survival time after completion of radiotherapy is 8.9 years, compared to 12.6 years in patients with $\mathrm{LBF}$ (late biochemical failure). Prostate cancer specific mortality risk was higher in the EBF cohort (Hazard ration $(\mathrm{HR})=6.75,95 \%$ Confidence Interval (C.I.) $=3.1-14.7$, P-value $<0.0001)$ compared to those with LBF. The risk of EBF was higher for patients with stage T2c-T4 disease compared those with stage T1-T2b disease (HR= 2.93, 95\% CI=1.30-6.58, P-value $=0.009$ ). On multivariate analysis the estimated hazard of risk of EBF increased 1.02 fold for each increase of $1 \mathrm{ng} / \mathrm{mL}$ in initial PSA. In the multi-variate model Gleason score also predicted EBF.

Conclusion: Patients with prostate cancer treated with neo-adjuvant androgen deprivation therapy and radiation therapy that develop EBF have a shorter median duration of prostate cancer specific mortality (PCSS) than those with LBF.

Keywords: Prostate cancer, androgen deprivation, biochemical failure, neo-adjuvant, radiotherapy
\end{abstract}

\section{Introduction}

Androgen deprivation therapy (ADT) combined with external beam radiotherapy (RT) improves outcome for patients with prostate cancer. Randomised trials of ADT and RT for locally advanced prostate cancer include RTOG 85-31, EORTC 22863, RTOG 86-10, RTOG 92-02, RTOG 94-13, TROG 96.01, and a study from Brigham and Women's Hospital, Boston [1]. We report an unplanned secondary analysis of ICORG 97-01, a randomised trial comparing 4 versus 8 months of neo-adjuvant ADT (NADT) prior to RT in localised prostate cancer. In a population of correlative interest, patients that fail biochemically within 2 years of a radical prostatectomy have an unfavourable prognosis [2]. We examined the hypothesis that this subgroup would also have an unfavourable prognosis in patients treated with neo-adjuvant hormonal therapy and radiation. The relationship between time of biochemical failure (BF) following RT and prostate-cancer-specific survival (PCSS) is assessed. Age, initial PSA (last PSA pre NADT), Gleason score, T-stage and duration of NADT were also assessed for correlation with EBF.

\section{Methods}

The ICORG 97-01 trial was a randomised phase III clinical trial, comparing 4 months versus 8 months (arms 1 and 2 respectively) of NADT followed by RT (70Gy). 276 patients with prostatic adenocarcinoma were accrued. Patients had localised, node negative disease.

\section{Eligibility criteria}

Inclusion criteria: PSA $>20 \mathrm{ng} / \mathrm{mL}$, Gleason score greater or equal to 7, or stage T3 or more, Karnofsky performance status (KPS) of greater or equal to 60. Exclusion criteria: Previous treatment for prostate cancer (other than transurethral resection of the prostate), bilateral orchidectomy, prior ADT, previous malignancy (other than non-melanoma skin cancer), and uncontrolled severe medical illnesses. Evaluation included history and physical examination, KPS assessment, complete blood count, liver function tests, chest radiograph, bone scan, and computed tomography $(\mathrm{CT})$ pelvis to exclude metastasis.

\section{Follow-up}

Year 1, monthly. Subsequent follow-up, 3 monthly. Included history, rectal examination, PSA, and toxicity assessment. Treatment failure was defined as clinical evidence of local or distant recurrence or BF.

\section{Design and procedures}

276 patients with adenocarcinoma of the prostate were enrolled in a phase III clinical trial comparing 4 versus 8 months of 


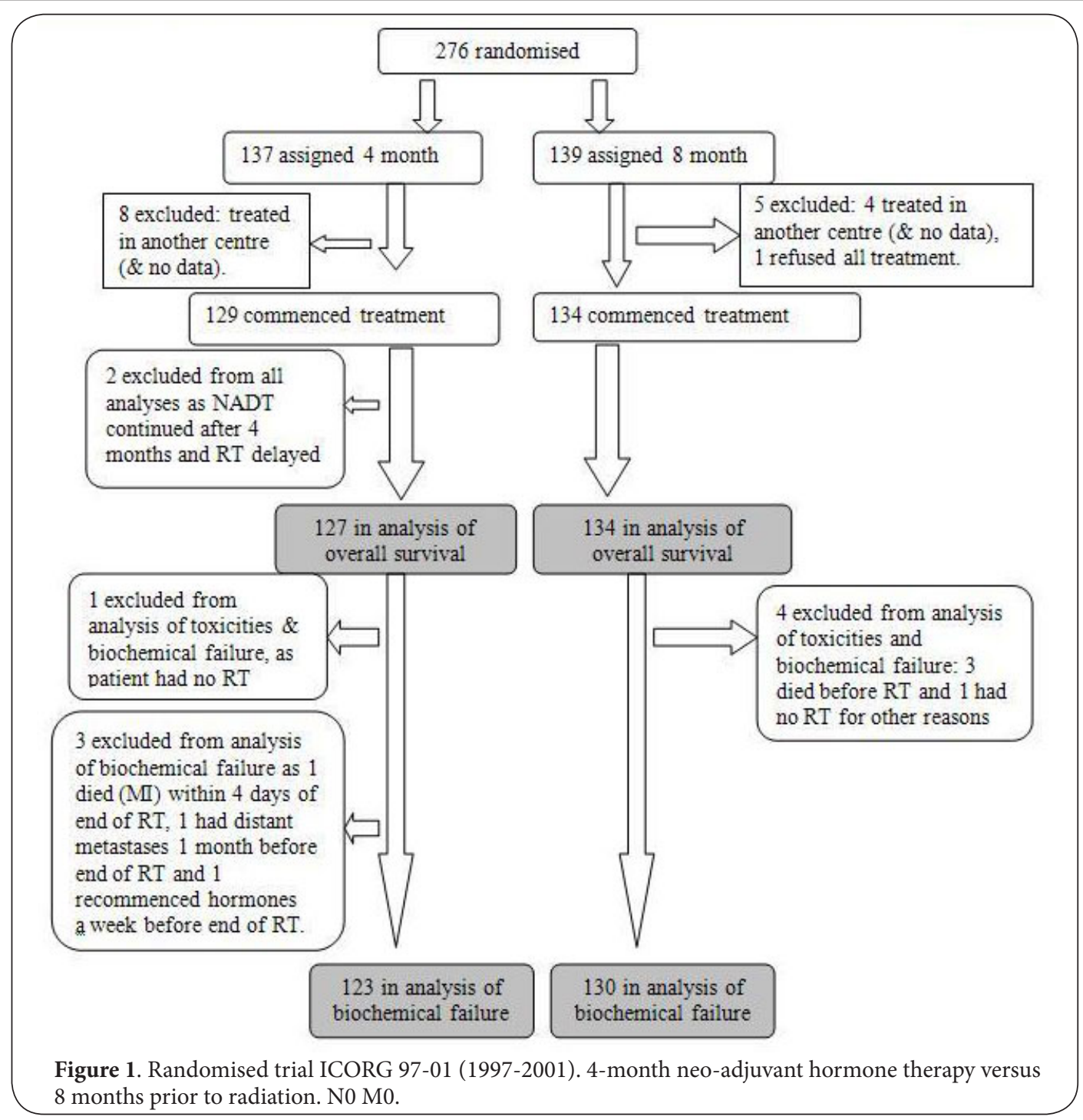

neo-adjuvant hormonal therapy followed by radiotherapy. All patients were node negative and had no metastases. The neo-adjuvant hormonal therapy was the LHRH agonist (Triptorelin $3.75 \mathrm{mg}$ im once monthly) combined with antiandrogen therapy (flutamide $250 \mathrm{mg}$ po 3 times daily) (Figure 1).

\section{Statistical analysis}

The definition of biochemical (PSA) failure in the trial protocol was in accordance with the American Society for Therapeutic Radiation statement but data were analysed using the new definition of $\mathrm{BF}$, defined as PSA >nadir after RT $+2 \mathrm{ug} / \mathrm{L}$ measured at least 18 months after completion of RT $[3,4,5]$. PSA doubling time was calculated as; PSADT (months) $=$ In $2 \times$ [(month 2 - month 1) / (In PSA2 - In PSA1)] [6]. Cause of death was taken from the death certificate and by a review of patient records if the death certificate was inadequate. To record death as caused by prostate cancer, there had to be documented metastatic prostate cancer or hormone-refractory prostate cancer (HRPC) and evidence that the PSA level was increasing at the time of the last follow-up visit despite the use of second-line hormones before death.

Time to PCSS was calculated from the date enrolled or date of consent (whichever was earliest) to the date of death if the death was disease related, or date of last contact. The Kaplan-Meier method was used to estimate survival times [7].

Cox regression analysis was used to determine univariate predictors of PCSS and time to EBF. Variables with a $\mathrm{P} \leq 0.10$ were included in the multivariate models. The proportional hazards assumption of the Cox model was tested through the graphical examination of the log-log plots of the variables used in the model. These plots formed approximate parallel straight lines as required. All statistical tests were two-sided and assessed for significance at the 0.05 level, except in analyses in which a Bonferroni adjustment for multiple comparisons was applied, in which case the significance level was 0.05 , divided by the number of comparisons. All 
Kelleher et al. Oncology Discovery 2013,

Table 1. Patient characteristics and clinical outcomes in the ICORG 97-01 study.

\begin{tabular}{|c|c|c|c|c|}
\hline & \multirow[t]{2}{*}{$n=253$} & \multicolumn{3}{|c|}{ Biochemical Failure (BF) } \\
\hline & & $\begin{array}{l}B F \\
n=110\end{array}$ & $\begin{array}{l}\mathrm{EBF} \\
\mathrm{n}=45\end{array}$ & $\begin{array}{l}\mathrm{LBF} \\
\mathrm{N}=65\end{array}$ \\
\hline \multicolumn{5}{|l|}{ Age (years) } \\
\hline Mean & 66.2 & 66.1 & 065.4 & 066.5 \\
\hline Median & $67 \cdot 3$ & $67 \cdot 4$ & $66 \cdot 5$ & $67 \cdot 8$ \\
\hline \multicolumn{5}{|l|}{ PSA } \\
\hline Mean ug/L & 22.7 & 28.5 & 39.7 & 20.7 \\
\hline Median ug/L & 14.6 & 18.3 & 21.9 & 14.2 \\
\hline Range ug/L & $0.6-262.8$ & $1.7-262.8$ & $5.7-262.8$ & $1.7-88.3$ \\
\hline$>20$ & $95(37 \%)$ & $48(44 \%)$ & $27(60 \%)$ & $21(32 \%)$ \\
\hline \multicolumn{5}{|l|}{ Gleason Score } \\
\hline$<7$ & $105(42 \%)$ & $32(29 \%)$ & $9(20 \%)$ & $23(35 \%)$ \\
\hline$=7$ & $115(45 \%)$ & $52(47 \%)$ & $24(53 \%)$ & $28(43 \%)$ \\
\hline$>7$ & $33(13 \%)$ & $26(24 \%)$ & $12(27 \%)$ & $14(22 \%)$ \\
\hline \multicolumn{5}{|l|}{ T Stage } \\
\hline $\mathrm{T} 1$ & $27(11 \%)$ & $9(8 \%)$ & $0(0 \%)$ & $9(14 \%)$ \\
\hline $\mathrm{T} 2$ & $73(29 \%)$ & $24(22 \%)$ & $7(16 \%)$ & $17(26 \%)$ \\
\hline $\mathrm{T} 3$ & $136(54 \%)$ & $67(61 \%)$ & $33(73 \%)$ & $34(52 \%)$ \\
\hline $\mathrm{T} 4$ & $17(7 \%)$ & $10(9 \%)$ & $5(11 \%)$ & $5(8 \%)$ \\
\hline \multicolumn{5}{|l|}{ T Stage Grp } \\
\hline $\mathrm{T} 1-\mathrm{T} 2 \mathrm{~b}$ & $97(38 \%)$ & $33(30 \%)$ & $7(16 \%)$ & $26(40 \%)$ \\
\hline $\mathrm{T} 2 \mathrm{c}-\mathrm{T} 4$ & $156(62 \%)$ & $77(70 \%)$ & $38(84 \%)$ & $39(60 \%)$ \\
\hline Salvage hormone therapy & $102(40 \%)$ & $99(90)$ & $43(96 \%)$ & $56(86 \%)$ \\
\hline $\begin{array}{l}\text { Median months from BF to } \\
\text { SHT (range) }(n=99)\end{array}$ & - & $3.4(0-35)$ & $3.2(0-35)$ & $4.1(0-33)$ \\
\hline $\begin{array}{l}\text { PSADT Median (range) } \\
\text { months }(\mathrm{n}=98)\end{array}$ & - & $2.1(0-74)$ & $1.5(0-62)$ & $4.4(0-74)$ \\
\hline $\begin{array}{l}\text { PSA nadir on SHT ng/mL } \\
\text { Median (range) } n=97\end{array}$ & - & $0.04(0-86)$ & $0.1(0-58)$ & $0.04(0-86)$ \\
\hline $\operatorname{HRPC}(\mathrm{n}=98)$ & - & $40(41 \%)$ & $28(65 \%)$ & $12(22 \%)$ \\
\hline Metastatic disease & $48(19 \%)$ & $46(42 \%)$ & $30(67 \%)$ & $16(25 \%)$ \\
\hline $\begin{array}{l}\text { Median months from BF to } \\
\text { metastases (range) }(n=46)\end{array}$ & - & $13.2(0-98)$ & $18.9(0-98)$ & $8.2(0-78)$ \\
\hline $\begin{array}{l}\text { Median months from BF to } \\
\text { death (range) }(n=48)\end{array}$ & - & $43(0-121)$ & $49(2-121)$ & $42(0-82)$ \\
\hline $\begin{array}{l}\text { Median months from } \\
\text { metastases to death (range) } \\
(\mathrm{n}=38)\end{array}$ & - & $21.2(0-96)$ & $25.7(2-96)$ & $15.1(0-64)$ \\
\hline Disease specific death & $38(15 \%)$ & $36(33 \%)$ & $26(58 \%)$ & $10(15 \%)$ \\
\hline
\end{tabular}

Data are for number of patients unless otherwise specified. Abbreviations: $\mathrm{PSA}=$ prostate-specific antigen; $\mathrm{SHT}=$ salvage hormone therapy; PSADT $=$ PSA doubling time (from BF to initiation of salvage hormones); HRPC= hormone-refractory prostate cancer (progression on SHT as evidenced by three consecutive PSA increases taken at least one week apart or findings on physical examination or imaging studies).

statistical analyses were performed using SPSS version 18 (SPSS, Inc., Chicago, IL, USA).

\section{Results}

The median follow-up, from consent to last contact, for all living patients was 111 months (range 54-158). The median follow-up, from the end of RT to last PSA test, for patients living free from BF was 96 months (range 57-141).

Median initial PSA was higher in patients with EBF, $22 \mathrm{ng} /$ $\mathrm{ml}$ compared with $14 \mathrm{ng} / \mathrm{ml}$ in those with LBF. None of those with T1 disease had EBF. Twenty-nine percent of those with T2 disease had EBF.

In addition, 58\% of those with PCSM had EBF compared to $15 \%$ of those with LBF. Salvage hormone treatment was
Table 2. Local or distant progression by biochemical failure (BF) $(n=253)$.

\begin{tabular}{ll|c|c|l}
\hline \multicolumn{4}{l}{ Failure } & \multicolumn{2}{l}{ Total } \\
\cline { 3 - 4 } & & No & Yes & \\
\cline { 3 - 5 } Local or distant progression & No & $139(97 \%)$ & 0 & $139(55 \%)$ \\
& Yes & $4(3 \%)$ & 110 & $114(45 \%)$ \\
Total & Total & 143 & 110 & 253 \\
\hline
\end{tabular}

received by $96 \%$ of those with EBF and by $86 \%$ of patients with LBF. The median time to salvage hormone therapy was 3 months for those with EBF and 4 months for those with LBF (Table 1) (Table 2). 30\% (77 of 253) of the patients died (28/77 had been diagnosed with a second primary cancer). 38 of the 77 had known metastatic disease and death was attributed to prostate cancer in all except one patient. Four patients of the 37 with metastatic disease whose death was caused by prostate cancer did not have HRPC and 2 did not have salvage hormones. One patient whose death was caused by prostate cancer had HRPC but no distant metastases (Table 3) (Figure 2).

PCSS curves by EBF/ LBF are curtailed at 120 months when 7 and 28 cases were remaining for EBF and LFB respectively (Figure 2). Patients with EBF had a median survival time of 107 months compared to 151 months for those with LBF. Using a Cox proportional hazards models, risk factors for EBF were evaluated as potential prognostic indicators by univariate analyses. We found initial PSA group, T-stage group and Gleason score group to be predictors of EBF, whereas age and arm were not predictive of EBF (Table 4).

In the multivariate model, after adjustment for the other variables, initial PSA, T-Stage group and Gleason score group remained as independent predictors for EBF (Table 4). The hazard (risk of EBF) is higher and thus the prognosis worse, for subjects with higher values of initial PSA ( $H R=1.019,95 \%$ $\mathrm{Cl}=1.01-1.02$, $\mathrm{P}$-value $<0.0001)$. The estimated hazard or risk of EBF increases by 1.02 times for each increase of $1 \mathrm{ng} / \mathrm{mL}$ in PSA, after adjustment for the effects of T-stage and Gleason score (e.g. there would be an estimated 10 fold increase in hazard for a patient with a PSA of $21 \mathrm{ng} / \mathrm{mL}$ compared to a patient with a PSA of $11 \mathrm{ng} / \mathrm{mL}$ ). The hazard (risk of EBF) is higher and thus the prognosis worse, for subjects with $\mathrm{T} 2 \mathrm{c}-\mathrm{T} 4$ disease $(\mathrm{HR}=4.38,95 \% \mathrm{Cl}=1.90-10.06, \mathrm{p}=0.001)$. Compared to those with $\mathrm{T} 1-\mathrm{T} 2 \mathrm{~b}$, patients with $\mathrm{T} 2 \mathrm{c}-\mathrm{T} 4 \mathrm{had}$ over 4 times the risk of EBF, after adjustment for initial PSA and Gleason score. The hazard (risk of EBF) is higher and thus the prognosis worse, for subjects with Gleason score $\geq 7$. Compared to those with Gleason score $<7$, patients with Gleason score $>7$ had 4.55 times the risk of EBF, after adjustment for initial PSA group and T-Stage group.

\section{Discussion}

This analysis of the ICORG 97-01 trial assesses the clinical significance of biochemical failure in the first 2 years post 
Kelleher et al. Oncology Discovery 2013,

http://www.hoajonline.com/journals/pdf/2052-6199-1-2.pdf

doi: 10.7243/2052-6199-1-2

Table 3. Cause of death.

\begin{tabular}{|c|c|c|c|c|c|c|c|c|}
\hline & \multicolumn{7}{|c|}{ Prostate Cancer Specific Mortality } & \multirow[t]{2}{*}{ Total deaths } \\
\hline & \multicolumn{3}{|c|}{ Progression/ Failure } & \multicolumn{2}{|c|}{ SHT } & \multicolumn{2}{|c|}{ HRPC } & \\
\hline & PSA & Local & Distant & Yes & No & Yes & No & \\
\hline Prostate cancer death (\%) & $34(77 \%)$ & $9(90 \%)$ & $37(97 \%)$ & $36(77 \%)$ & $2(7 \%)$ & $34(100 \%)$ & $4(9 \%)$ & $38(49)$ \\
\hline Death from other cause (\%) & $10(23 \%)$ & $1(10 \%)$ & $1(3 \%)$ & $11(23 \%)$ & $28(93 \%)$ & 0 & $39(91 \%)$ & $39(51)$ \\
\hline Total & - & 10 & 38 & 47 & 30 & 34 & 43 & 77 \\
\hline
\end{tabular}

SHT= salvage hormone therapy

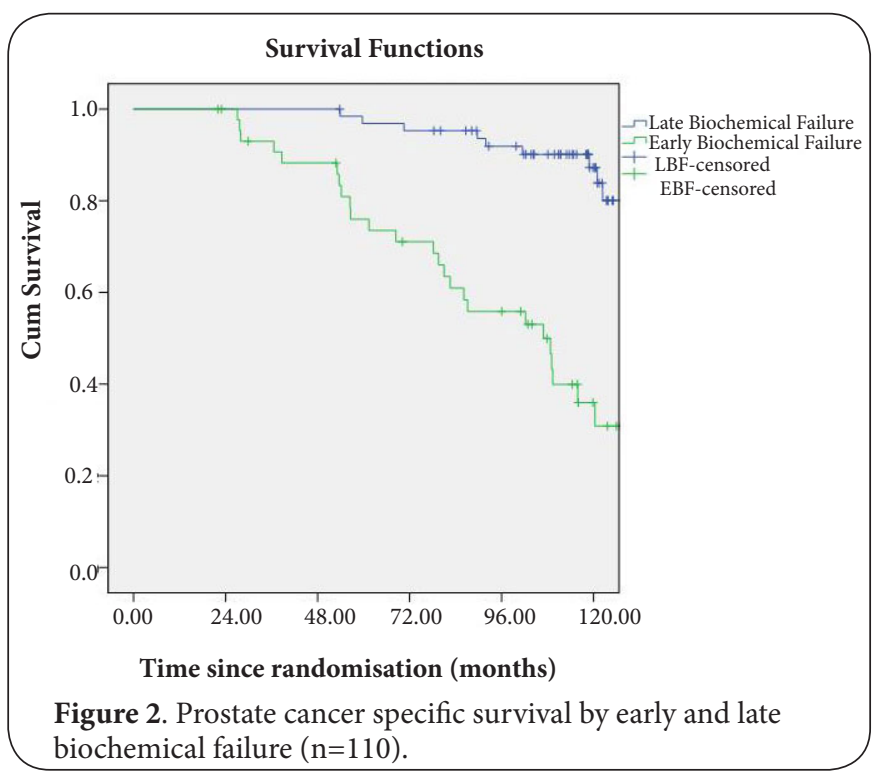

Table 4. Cox Regression Analysis of Early Biochemical Failure $(n=253)$.

\begin{tabular}{|c|c|c|c|c|c|c|c|}
\hline \multirow[t]{2}{*}{ Covariate } & \multirow[t]{2}{*}{$\begin{array}{l}\text { Reference } \\
\text { category }\end{array}$} & \multicolumn{3}{|c|}{ Univariate analysis } & \multicolumn{3}{|c|}{$\begin{array}{l}\text { Multivariate analysis - final } \\
\text { step }\end{array}$} \\
\hline & & HR & $95 \% \mathrm{CI}$ & $\mathbf{p}$ & HR & 95\% CI & $\mathbf{p}$ \\
\hline Age & - & 0.98 & $0.93-1.03$ & 0.353 & - & - & - \\
\hline Initial PSA & - & 1.02 & $1.01-1.02$ & $<0.0001$ & 1.019 & $1.01-1.02$ & $<0.0001$ \\
\hline $\begin{array}{l}\text { T-Stage } \\
\text { T2c-T4 }\end{array}$ & $\begin{array}{l}\text { T-Stage } \\
\text { T1-T2b }\end{array}$ & 3.66 & $1.63-8.20$ & 0.002 & 4.38 & $1.90-10.06$ & 0.001 \\
\hline $\begin{array}{l}\text { Gleason } \\
\text { score }\end{array}$ & $\mathrm{GS}<7$ & - & - & 0.002 & - & - & $<0.0001$ \\
\hline$=7$ & - & 2.74 & $1.27-5.89$ & 0.010 & 4.70 & $2.1-10$ & $<0.0001$ \\
\hline$>7$ & - & 4.84 & $2.04-11.5$ & $<0.0001$ & 4.55 & $1.9-11$ & 0.001 \\
\hline $\begin{array}{l}4 \mathrm{mths} \\
\text { Hormones }\end{array}$ & $8 \mathrm{mths}$ & 0.94 & $0.52-1.68$ & 0.831 & - & - & - \\
\hline
\end{tabular}

HR, hazard ratio or relative risk; CI, confidence interval; PSA, prostate-specific antigen.

completion of radiotherapy. In patients with $\mathrm{EBF}$, median survival time from the time of randomization was 107 months compared to 151 months for those with LBF. The current literature on use of EBF as a surrogate of disease specific mortality is summarized in (Table 5) with variation in study design and treatment administered as well as historic variation in the definition of biochemical failure used. The results from this supplementary analysis of the ICORG 97-01 trial and other similar trials of radiotherapy with neo-adjuvant hormones could benefit from a succeeding inter-study comparator review with respect to the clinical significance of biochemical failure in the first 2 years. Study design variations and lack of individualized data would demand an international collaborative effort to perform a meaningful meta-analysis. The results however would be of great practical interest to patients and physicians confronted with the problem of early biochemical relapse.

Previous studies have found that rapid PSA increases, or short post treatment PSA doubling times, after local therapy are associated with the development of metastatic disease and PCSM [12,13-17]. D'Amico et al., in a retrospective analysis demonstrated that a short PSA doubling time of less than 3 months meets statistical criteria for being a surrogate endpoint for PCSS. However, metrics such as PSA doubling time and PSA velocity can be confounded by the methods used and frequency of PSA measurements.

Furthermore, de Crevoisier et al., reported that a PSA decline 6 weeks after the start of EBRT when used as monotherapy and 3 months after the start of ADT in patients treated with combined ADT and EBRT is predictive of progression and survival [18]. Patients with a T stage T2C-4 compared to T1-2B were 4 times more likely to have EBF. We report an association between EBF and death from prostate cancer. While this association is not unexpected, it's quantification is nonetheless important. This observation is consistent with The Transman study TROG $96.01[19,20]$. Our study gives clinicians further insight into the natural history of biochemically recurrent prostate cancer after RT and NADT.

It had previously been established that the natural history of prostate cancer relapsing post radical prostatectomy is that the median interval from biochemical relapse to the identification of metastasis is 8 years and the median time from metastatic disease to death is 5 years [21]. The ICORG study by comparison has shorter intervals. The 'Pound study', in which $44.7 \%$ of patients had early biochemical failure, found that the time to biochemical relapse was predictive of the probability of and time to development of metastatic disease $(p<.001)$. It would appear from the ICORG 97-01 study that EBF identifies an important subgroup with a more aggressive natural history and short survival. In patients treated with neo-adjuvant androgen deprivation and radiation EBF had a median PCSS time of 8.9 years. Those experiencing LBF had a PCSS time of 12.6 years. Therefore EBF defines a high-risk cohort for PCSM.

Predictors of biochemical recurrence are well established and we sought to establish the association of some of the 
Kelleher et al. Oncology Discovery 2013,

http://www.hoajonline.com/journals/pdf/2052-6199-1-2.pdf

doi: $10.7243 / 2052-6199-1-2$

Table 5. Clinical studies relevant to EBF as a surrogate for disease specific mortality.

\begin{tabular}{|c|c|c|c|c|c|}
\hline Clinical study & Number of patients & Nature of study & Early biochemical failure & Main study findings & Time to biochemical progression \\
\hline $\begin{array}{l}\text { Pound et al. } 1999 \\
\text { Johns Hopkins }\end{array}$ & 1997 & $\begin{array}{l}\text { Retrospective review of } \\
\text { surgical series }\end{array}$ & $\begin{array}{l}136 / 304(44.7 \% \text { of patients } \\
\text { with BF) }\end{array}$ & $\begin{array}{l}\text { Median time to metastasis } \\
\text { from time of PSA eleva- } \\
\text { tion }=8 \text { years. } \\
\text { Median time to death from } \\
\text { metastasis }=5 \text { years }\end{array}$ & $\begin{array}{l}\text { Time to biochemical progression } \\
\text { was predictive of probability and } \\
\text { time to development of metastatic } \\
\text { disease }(\mathrm{P}<.001)\end{array}$ \\
\hline $\begin{array}{l}\text { Freedland et al. } 2005 \\
\text { Johns Hopkins }\end{array}$ & 379 & $\begin{array}{l}\text { Retrospective study to de- } \\
\text { fine risk factors for prostate } \\
\text { cancer specific death post } \\
\text { radical prostatectomy }\end{array}$ & $\begin{array}{l}\text { In this study segregation at } \\
3 \text { years after surgery to BF } \\
\text { found to be the best risk } \\
\text { stratification }\end{array}$ & $\begin{array}{l}\text { PSADT, Gleason score and } \\
\text { time to BF are significant } \\
\text { risk factors for prostate } \\
\text { specific mortality }\end{array}$ & $\begin{array}{l}\text { Time from surgery to } \mathrm{BF}(<\text { or }=3 \\
\text { vs. }>3 \text { years) significant risk factor } \\
\text { for time to prostate cancer specific } \\
\text { mortality }\end{array}$ \\
\hline $\begin{array}{l}\text { Denham et al. } 2008 \\
\text { Newcastle, Australia }\end{array}$ & 802 & $\begin{array}{l}\text { TROG } 96.01 \text { trial } \\
\text { Locally advanced prostate } \\
\text { cancer. } \\
\text { RT alone or with short term } \\
\text { ADT } 3 / 6 \text { months }\end{array}$ & $\begin{array}{l}\text { Time to BF was better than } \\
\text { PSADT at predicting the } \\
\text { trial finding and satisfied all } \\
\text { four Prentice criteria at cut- } \\
\text { offs }<1.5,<2,<2.5 \text { yrs }\end{array}$ & $\begin{array}{l}6 \text { months ADT before and } \\
\text { during RT beneficial }\end{array}$ & $\begin{array}{l}\text { TTBF is a useful surrogate end- } \\
\text { point for prostate cancer specific } \\
\text { mortality }\end{array}$ \\
\hline Sandler et al. 2003 & 1551 & $\begin{array}{l}\text { RTOG 92-02 } \\
\text { Short vs. long term ADT } \\
\text { T2c-4 prostate cancer }\end{array}$ & $\begin{array}{l}\text { Analysis by Valicencti JCO } \\
\text { 2005;23:4549 showed that } \\
\text { PSADT useful surrogate }\end{array}$ & $\begin{array}{l}\text { The RTOG } 92-02 \text { trial } \\
\text { supports the addition of LT } \\
\text { adjuvant AD to STAD with } \\
\text { RT for T2c-T4 PC. In the } \\
\text { exploratory subset analysis } \\
\text { of patients with Gleason } \\
\text { scores } 8 \text { to } 10, \mathrm{LT} \text { adjuvant } \\
\text { AD resulted in a survival } \\
\text { advantage }\end{array}$ & $\begin{array}{l}\text { Time to treatment failure not a } \\
\text { surrogate for prostate cancer spe- } \\
\text { cific mortality. Failed } 4^{\text {th }} \text { Prentice } \\
\text { criterion }\end{array}$ \\
\hline $\begin{array}{l}\text { Buyyounouski et al. } 2008 \\
\text { Fox Chase, Philadelphia }\end{array}$ & 1174 & $\begin{array}{l}\text { T1C-T3Nx-N0M0 } \\
\text { Prostate cancer patients } \\
\text { treated with 3D conformal } \\
\text { RT }\end{array}$ & 211 patients had BF of 1174 & $\begin{array}{l}\text { Interval to } \mathrm{BF}<18 \text { months, } \\
\text { Gleason score } 7-10 \text {, PSA } \\
\text { nadir }>\text { or }=2 \mathrm{ng} / \mathrm{ml} \text { and } \\
\text { decreasing RT dose were } \\
\text { predictive of distant } \\
\text { metastasis }\end{array}$ & $\begin{array}{l}\text { On Cox proportional hazards } \\
\text { modelling an interval to } \mathrm{BF}<18 \\
\text { months was the only predictor of } \\
\text { prostate cancer specific mortality } \\
(\mathrm{p}=0.0003)\end{array}$ \\
\hline
\end{tabular}

parameters (initial PSA, Gleason score and T-stage) with biochemical recurrence in the first two years post RT and NADT. Walz et al., (2009) devised a predictive nomogram of recurrent disease using Cox regression models of 2911 patients post RRP. They found that pathological Gleason sum 7 or greater, seminal vesicle invasion and lymph node involvement were the most powerful predictors of biochemical recurrence [22]. A further study of biochemical recurrence after radical prostatectomy found that Gleason grade and pathologic stage $(p<0.002)$ were predictive of biochemical recurrence [23]. In our study, established predictive factors: initial PSA, Gleason score and T-stage were assessed to see if they were associated with EBF. We found that initial PSA, T-Stage group and Gleason score group predicted EBF. Compared to those with T1-T2b stage disease patients with $\mathrm{T} 2 \mathrm{c}-\mathrm{T} 4$ prostate cancer had a greater risk of EBF, after adjustment for initial PSA and Gleason score group. A study of similar design to the ICORG 97-01 was that of the Trans-Tasman Radiation Oncology Group (TROG) 96.01 Trial [20]. That study of 802 men with locally advanced prostate cancer compared treating prostate cancer with RT alone to 3 or 6 months of maximum short-term ADT before and during RT. In a subsequent analysis they examined time to BF (TTBF) and PSADT as surrogate endpoints for PCSM. TTBF was found to be a useful vicarious endpoint, and more particularly TTBF in a cut point band from less than 1.5 to less than 2.5 years predicted the endpoints of the trial. All four Prentice surrogacy criteria [24] were satisfied using the less than 1.5 , less than 2 , and less than 2.5 year cut-offs.

The distinction between prognostic factors and those that predict response to therapy is also clinically important.
Men with a PSA doubling time after radical prostatectomy of less than 6 months have a worse prognosis overall than those with a PSA doubling time of 6 months or longer, but they derive a greater benefit from salvage therapy relative to untreated patients [2]. This may indicate that many men with a PSA doubling time of 6 months or longer have biologically less aggressive disease that is less likely to result in metastatic disease or death during their lifetime. An analysis of the RTOG 92-02 study of short versus long term ADT in T2c-4 prostate cancer found that time to treatment failure did not satisfy the 4th Prentice criterion (i.e., that the surrogate mediates the effect of initial treatment on the true endpoint) $[25,26]$. That study was designed so that all patients received goserelin and flutamide for 4 months before and during RT and were then randomised to no further ADT or 24 months of goserelin. The postulated reason that the 4th Prentice criterion was not satisfied was that a proportion of patients on long term ADT that had recurrent disease were hormone insensitive at time of PSA relapse and therefore were insensitive to salvage ADT [27]. The TROG 96.01 study randomised patients to 0,3 or 6 months ADT before and during RT and the ICORG 97-01 study randomised to 4 versus 8 months NADT.

Because of the long natural history of prostate cancer, randomized trials designed to detect statistically significant differences in mortality often are prohibitive in terms of size, duration, and cost. The use of surrogate endpoints substantially decreases the size and duration of clinical trials, allowing more rapid prospective testing of hypotheses and potentially accelerating development of improved cancer treatment. Therefore an analysis of the natural history of EBF in this 
Kelleher et al. Oncology Discovery 2013,

context is even more important. Ultimately this study further supports the TROG 96.01 study that BF at or before 2 years post RT is associated with an increased risk of PCSM. Perhaps before these finding of time to biochemical failure and risk of PCSM are incorporated into routine practice a prospective clinical trial of time to biochemical failure and PCSM should be initiated. That study should obviate the inherent flaws in the clinically convenient but somewhat arbitrary selection of the 2-year cut-off in the ICORG 97-01 supplementary analysis or the categorical cohort based approach in the TROG 96.01 study. A continuous model that discovers the optimal abscission time point and then extended actuarial documentation of the longitudinal PCSM outcomes are required.

Finally a previous Cochrane review did compare neoadjuvant hormone therapy with radiotherapy versus radiotherapy alone for localized and locally advanced prostate cancer [28]. Outcome measures included biochemical free survival, and clinical disease free survival. Respective totals were 1.93 [C.I. 1.45,2.56] and 1.86 [C.I. 1.43,2.40] favouring combined treatment. Ultimately only individualized patient data from other previous studies of neo-adjuvant hormonal therapy and radiotherapy will provide meaningful comparator data to out study and that of Denham in the Trans-Tasman study.

\section{List of abbreviations}

ICORG: Irish Clinical Oncology Research Group

EBF: Early biochemical failure. Defined for the purposes of this study as biochemical relapse within 2 years of completion of 3D- conformal radiotherapy.

The definition of biochemical (PSA) failure in the ICORG 97-01 trial protocol was in accordance with the American Society for Therapeutic Radiation and Oncology (ASTRO) consensus statement (A) but data was analyzed using the new definition of biochemical failure, defined as PSA >nadir after $\mathrm{RT}+2 \mathrm{ng} / \mathrm{mL}(\mathrm{B}, \mathrm{C})$.

A. American Society for Therapeutic Radiology and Oncology: Consensus Statement. Guidelines for PSA following radiation therapy. Int J Radiat Oncol Biol Phys 1997;37:1035-1041.

B. Pickles T, Kim-Sing C, Morris WJ, et al., Evaluation of the Houston biochemical relapse definition in men treated with prolonged neo-adjuvant and adjuvant androgen ablation and assessment of follow-up lead-time bias. Int J Radiat Oncol Biol Phys 2003;57:11-18. 3. C. Roach M, Hanks G, Thames H, et al., Defining biochemical failure following radiotherapy with or without hormone therapy in men with clinically localized prostate cancer: Recommendations of the RTOG-ASTRO Phoenix consensus conference. Int J Radiat Oncol Biol Phys 2006; 65:965-974.

LBF: Late biochemical failure. Defined for the purposes of this study as biochemical relapse greater than 2 years post completion of 3Dconformal radiotherapy. As per the definitions A-C above.

A 2-year cut off was decided upon prior to data analysis as practical duration to assist the physician in the clinic.

\section{Competing interests}

The authors declare that they have no competing interests.

\section{Authors' contributions}

Fergal C. Kelleher and John G. Armstrong, conceived the manuscript concept, reviewed the literature, contribute to statistical analysis and wrote the manuscript. Mary Dunne, performed all statistical analysis and wrote the manuscript. Ian Collins, devised computerised systems for the ICORG 97-01 study.

M. Finn and C. O'Shea, documented patients

data for the ICORG 97-01 study.

Acknowledgement and funding

Financial funding provided by Ipsen Pharmaceuticals,

Friends of St. Luke's Hospital and Private Donors.

Publication history

Received: 29-Jan-2013 Revised: 02-Apr-2013

Accepted: 05-Apr-2013 Published: 10-Apr-2013

\section{References}

1. Armstrong JG, Gillham CM, Dunne MT, Fitzpatrick DA, Finn MA, Cannon ME, Taylor JC, O'Shea CM, Buckney SJ and Thirion PG: A randomized trial (Irish clinical oncology research group 97-01) comparing short versus protracted neoadjuvant hormonal therapy before radiotherapy for localized prostate cancer. Int J Radiat Oncol Biol Phys 2011, 81:35-45. | Article I PubMed

2. Trock BJ, Han M, Freedland SJ, Humphreys EB, DeWeese TL, Partin AW and Walsh PC: Prostate cancer-specific survival following salvage radiotherapy vs observation in men with biochemical recurrence after radical prostatectomy. JAMA 2008, 299:2760-9. | Article | PubMed Abstract | PubMed Full Text

3. Consensus statement: guidelines for PSA following radiation therapy. American Society for Therapeutic Radiology and Oncology Consensus Panel. Int J Radiat Oncol Biol Phys 1997, 37:1035-41. | Article | PubMed

4. Pickles T, Kim-Sing C, Morris WJ, Tyldesley S and Paltiel C: Evaluation of the Houston biochemical relapse definition in men treated with prolonged neoadjuvant and adjuvant androgen ablation and assessment of follow-up lead-time bias. Int J Radiat Oncol Biol Phys 2003, 57:11-8. | Article | PubMed

5. Roach M, 3rd, Hanks G, Thames H, Jr., Schellhammer P, Shipley WU, Sokol GH and Sandler H: Defining biochemical failure following radiotherapy with or without hormonal therapy in men with clinically localized prostate cancer: recommendations of the RTOG-ASTRO Phoenix Consensus Conference. Int J Radiat Oncol Biol Phys 2006, 65:965-74. | Article | PubMed

6. Patel A, Dorey F, Franklin J and deKernion JB: Recurrence patterns after radical retropubic prostatectomy: clinical usefulness of prostate specific antigen doubling times and log slope prostate specific antigen. J Urol 1997, 158:1441-5. | Article | PubMed

7. Kaplan EL, Meier P: Nonparametric estimation from incomplete observations. Journal American Statistical Association 1958, 53:457-481.

8. Efstathiou JA, Bae K, Shipley WU, Hanks GE, Pilepich MV, Sandler HM and Smith MR: Cardiovascular mortality after androgen deprivation therapy for locally advanced prostate cancer: RTOG 85-31. J Clin Oncol 2009, 27:92-9. | Article | PubMed Abstract | PubMed Full Text

9. Keating NL, O'Malley AJ and Smith MR: Diabetes and cardiovascular disease during androgen deprivation therapy for prostate cancer. J Clin Oncol 2006, 24:4448-56. | Article | PubMed

10. D'Amico AV, Denham JW, Crook J, Chen MH, Goldhaber SZ, Lamb DS, Joseph D, Tai KH, Malone S, Ludgate C, Steigler A and Kantoff PW: Influence of androgen suppression therapy for prostate cancer on the frequency and timing of fatal myocardial infarctions. J Clin Oncol 2007, 25:2420-5. | Article | PubMed

11. Alibhai SM, Duong-Hua M, Sutradhar R, Fleshner NE, Warde P, Cheung AM and Paszat LF: Impact of androgen deprivation therapy on cardiovascular disease and diabetes. J Clin Oncol 2009, 27:3452-8. | Article I PubMed

12. Freedland SJ, Humphreys EB, Mangold LA, Eisenberger M, Dorey FJ, Walsh PC and Partin AW: Risk of prostate cancer-specific mortality following biochemical recurrence after radical prostatectomy. JAMA 2005, 294:433-9. | Article | PubMed

13. Okotie OT, Aronson WJ, Wieder JA, Liao Y, Dorey F, De KJ and Freedland $\mathrm{SJ}$ : Predictors of metastatic disease in men with biochemical failure following radical prostatectomy. J Urol 2004, 171:2260-4. | Article | 
Kelleher et al. Oncology Discovery 2013,

\section{PubMed}

14. D'Amico AV, Cote K, Loffredo M, Renshaw AA and Schultz D: Determinants of prostate cancer-specific survival after radiation therapy for patients with clinically localized prostate cancer. J Clin Oncol 2002, 20:4567-73. | Article | PubMed

15. Hanlon AL, Horwitz EM, Hanks GE and Pollack A: Short-term androgen deprivation and PSA doubling time: their association and relationship to disease progression after radiation therapy for prostate cancer. Int $J$ Radiat Oncol Biol Phys 2004, 58:43-52. | Article | PubMed

16. Hanlon AL, Diratzouian H and Hanks GE: Posttreatment prostate-specific antigen nadir highly predictive of distant failure and death from prostate cancer. Int J Radiat Oncol Biol Phys 2002, 53:297-303. | Article I PubMed

17. Kim-Sing $C$ and Pickles T: Intervention after PSA failure: examination of intervention time and subsequent outcomes from a prospective patient database. Int J Radiat Oncol Biol Phys 2004, 60:463-9. | Article | PubMed

18. de Crevoisier R, Slimane K, Messai T, Wibault P, Eschwege F, Bossi A, Koscielny S, Bridier A, Massard C and Fizazi K: Early PSA decrease is an independent predictive factor of clinical failure and specific survival in patients with localized prostate cancer treated by radiotherapy with or without androgen deprivation therapy. Ann Oncol 2010, 21:808-14. | Article | PubMed

19. Denham JW, Steigler A, Wilcox C, Lamb DS, Joseph D, Atkinson C, Matthews J, Tai KH, Spry NA, Christie D, Gleeson PS, Greer PB and D'Este $C$ : Time to biochemical failure and prostate-specific antigen doubling time as surrogates for prostate cancer-specific mortality: evidence from the TROG 96.01 randomised controlled trial. Lancet Oncol 2008, 9:105868. | Article | PubMed

20. Denham JW, Steigler A, Lamb DS, Joseph D, Turner S, Matthews J, Atkinson C, North J, Christie D, Spry NA, Tai KH, Wynne C and D'Este C: Short-term neoadjuvant androgen deprivation and radiotherapy for locally advanced prostate cancer: 10-year data from the TROG 96.01 randomised trial. Lancet Oncol 2011, 12:451-9. | Article | PubMed

21. Pound CR, Partin AW, Eisenberger MA, Chan DW, Pearson JD and Walsh PC: Natural history of progression after PSA elevation following radical prostatectomy. JAMA 1999, 281:1591-7. | Article | PubMed

22. Walz J, Chun FK, Klein EA, Reuther A, Saad F, Graefen M, Huland H and Karakiewicz PI: Nomogram predicting the probability of early recurrence after radical prostatectomy for prostate cancer. J Urol 2009, 181:601-7; discussion 607-8. | Article | PubMed

23. Molitierno J, Evans A, Mohler JL, Wallen E, Moore D and Pruthi RS Characterization of biochemical recurrence after radical prostatectomy. Urol Int 2006, 77:130-4. | Article | PubMed

24. Prentice RL: Surrogate endpoints in clinical trials: definition and operational criteria. Stat Med 1989, 8:431-40. | Article | PubMed

25. Valicenti RK, DeSilvio M, Hanks GE, Porter A, Brereton H, Rosenthal SA, Shipley WU and Sandler HM: Posttreatment prostatic-specific antigen doubling time as a surrogate endpoint for prostate cancer-specific survival: an analysis of Radiation Therapy Oncology Group Protocol $92-$ 02. Int J Radiat Oncol Biol Phys 2006, 66:1064-71. | Article | PubMed

26. Horwitz EM, Bae K, Hanks GE, Porter A, Grignon DJ, Brereton HD, Venkatesan V, Lawton CA, Rosenthal SA, Sandler HM and Shipley WU: Ten-year follow-up of radiation therapy oncology group protocol 92 02: a phase III trial of the duration of elective androgen deprivation in locally advanced prostate cancer. J Clin Oncol 2008, 26:2497-504. Article | PubMed

27. Collette L, Burzykowski T and Schroder FH: Prostate-specific antigen (PSA) alone is not an appropriate surrogate marker of long-term therapeutic benefit in prostate cancer trials. Eur J Cancer 2006, 42:134450. | Article | PubMed

28. Kumar S, Shelley M, Harrison C, Coles B, Wilt TJ and Mason MD: Neoadjuvant and adjuvant hormone therapy for localised and locally advanced prostate cancer. Cochrane Database Syst Rev 2006, CD006019. | Article | PubMed

\section{Citation:}

Kelleher F C, Dunne M T, Collins I M, Finn M A, O’Shea $\mathrm{C} \mathrm{M}$ and Armstrong J G: The clinical significance of biochemical failure in the first 2 years in patients treated with neo-adjuvant androgen deprivation and radiotherapy for prostate cancer. Oncology Discovery 2013, 1:2. http://dx.doi.org/10.7243/2052-6199-1-2 